\title{
Perception of needs and responses in food security: divergence between households and stakeholders
}

\author{
Anne-Marie Hamelin ${ }^{1, *}$, Céline Mercier ${ }^{2}$ and Annie Bédard ${ }^{1}$ \\ 'Department of Food Sciences and Nutrition, Pavillon Paul-Comtois, Université Laval, 2425 rue de l'Agriculture, \\ Québec City, Canada GIV 0A6: ${ }^{2}$ Department of Social and Preventive Medicine, Université de Montréal, Canada
}

Submitted 23 March 2007: Accepted 7 July 2008: First published online 2 September 2008

\begin{abstract}
Objectives: The aim of the study was (i) to describe the needs of food-insecure households and their assessment of community programmes, as expressed by households and perceived by stakeholders; and (ii) to examine the similarities and differences between households' and stakeholders' perceptions in Quebec City area.

Design/setting/subjects: A semi-structured interview and sociodemographic questionnaire with fifty-five households and fifty-nine stakeholders (community workers, managers, donor agencies). The transcriptions were subjected to content analysis and inter-coder reliability measurement.

Results: The respondents' perceptions converge towards three main categories of needs: needs specific to food security, conditions necessary for achieving food security and related needs. There was agreement on the necessity of better financial resources, although the impact of financial resources alone may be uncertain in the opinion of some stakeholders. Different perceptions of needs and of their fulfilment by community programmes emerge between both groups. Despite households found positive aspects, they complained that quality of food and access were major needs neglected. Their account suggests overall a partial fit between the programmes and food security needs; even a combination of programmes (e.g. collective kitchens, purchasing groups, community gardens) was insufficient to adequately meet these needs. In contrast, most stakeholders perceived that the household's primary need was a basic amount of food and that the households were satisfied with programmes.

Conclusions: It is urgent to evaluate the overall effect of community programmes on specific aspects of household food insecurity. The results emphasise that community programmes alone cannot bring about social change needed to prevent food insecurity.
\end{abstract}

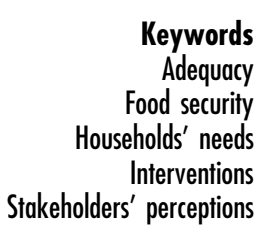

Socio-economic inequality, which creates poverty, is reflected in the ability of households to maintain a satisfactory and stable food situation ${ }^{(1)}$. In Canada, one household out of eleven experienced food insecurity in 2004 (worrying about access to food, compromises in food quality or restriction of food intake) ${ }^{(2)}$. Food insecurity, which is rooted in situations marked by poverty ${ }^{(3-7)}$, may compromise nutritional quality ${ }^{(5,8-11)}$ and health ${ }^{(9,10,12,13)}$. On a societal level, food insecurity is related to problems in learning and productivity, increased health-care needs and intensification of exclusion ${ }^{(9,14,15)}$. According to several authors, governments have the indisputable responsibility to put in place public policies for dealing adequately with food insecurity, including sustainable food systems and improved income conditions ${ }^{(10,16,17)}$.

The most common response to food insecurity during the 1980 s was food donations ${ }^{(18)}$. More recently, community programmes, such as collective kitchens, have become popular. In the opinion of some, these programmes could improve food security by promoting skill learning and social $\operatorname{contacts}^{(19,20)}$. Nevertheless, despite their steady increase since the 1990s, household food insecurity does not seem to have diminished ${ }^{(21)}$. In 2002, a government subsidies programme in food security was launched in Quebec, but its decision-making processes did not leave much room for new initiatives besides the usual interventions ${ }^{(22)}$. The persistence of food insecurity raises questions about the actual effectiveness of the programmes, and makes it legitimate to question the perceptions of community workers and decision-makers with regard to the needs of the households. To our knowledge, no Canadian study has directly questioned food-insecure households about their needs and their fulfilment by so-called food security activities.

The present paper aims (i) to describe the needs of food-insecure households and their assessment of community programmes, as expressed by the households 
and as perceived by stakeholders; and (ii) to examine the similarities and differences between the issues expressed by both groups. This is part of a case study of the fit between food security programmes and the needs of food-insecure households in the Quebec City area (AM Hamelin, C Mercier, J Gauthier, AM Hamelin, C Mercier and A Bédard, unpublished results).

\section{Methods}

\section{Sampling}

Food-insecure households in Quebec City were recruited with the help of organisations connected to the community, and by means of advertisements in newspapers and flyers in homes and schools in the targeted neighbourhoods. Interested households contacted the research assistant by telephone. Their food insecurity status was then estimated using the Radimer/Cornell Index ${ }^{(23)}$, and their participation in community programmes for food security (CPFS) over the previous year was noted. Homeless persons, drug addicts, persons aged 75 years or older, and persons living in institutions were excluded to ensure that participants reflect the mainstream households.

Three groups of stakeholders in Quebec City were approached: community workers working directly with households in situations of poverty and food insecurity; managers of organisations that administer food security measures or assistance to poverty-stricken persons; and representatives from donor agencies that support food security activities. Several of these were asked to be part of an on-the-ground committee to facilitate relationships between the researchers and resource persons in the field, and to ensure that information was shared effectively. The study was approved by the research ethics committees of Université Laval and of the Centre de santé et des services sociaux de la Vieille-Capitale.

\section{Data collection}

Semi-structured individual interviews of approximately 90 min were conducted, and audio-recorded, with fifty-five adults from the households and fifty-nine stakeholders. In order to cover the topic properly, the interview schedule consisted of both open-ended questions and a predetermined set of sub-questions about the experience of food insecurity and the needs related to it. The probing technique was used. Households participating in CPFS, field workers and managers were also asked to describe their perception of how households assessed these activities, and to what extent they contributed to meeting their needs. Donor agencies were only asked their general perception of how the households appreciated the CPFS. The interviews ended with a complementary sociodemographic questionnaire and, for the households, three questions about food insecurity from the Canadian Community Health Survey ${ }^{(24)}$.

\section{Data analysis}

Recordings were transcribed in full and then subjected to content analysis using NVivo $2 \cdot 0$. The coding scheme was designed using a framework that had been developed from an ethnographic study of food insecurity in the Quebec City area ${ }^{(25)}$. According to this framework, the needs related to food security were derived (adequate amount of food; acceptable quality of food and diet; regular sustained access to food; feeling of control over food situation; feeling of physical and psychological (dignity) well-being; and appropriate strategies for obtaining, managing and consuming food); these themes were used to structure both the interview schedule and the coding scheme.

The coding scheme was also enhanced by themes that emerged from participants' accounts, allowing the creation of categories and subcategories of needs. Content analysis led to a synthesis of household needs and their fulfilment through CPFS, and then to a comparison between households' accounts and stakeholders' perception. Two indicators were calculated to permit these comparisons: the percentage of respondents who mentioned at least one need appertaining to a given category, and the ratio between the total mentions in a given category (by adding the mentions of the different subcategories) and the number of respondents who expressed at least one need in that category ${ }^{(26)}$. Inter-coder reliability was measured over a sample of interviews with households ( $n$ 4), community workers ( $n$ 5), managers ( $n$ 3) and donor agencies ( $n$ 2), coded by two team members ${ }^{(27)}$. Reliability, before discussion of disagreements, was on average 70, 79, 66 and $81 \%$, respectively. The main errors in interpretation concerned accounts about assessment of interventions (21\%) and manifestations of insecurity (9\%). All disagreements were entirely resolved through discussion with the principal researcher.

The fact that the final household interviews yielded no new ideas suggests an attainment of theoretical saturation. Furthermore, the triangulation of perspectives adds credibility to the data. In addition, results were respectively submitted to households ( $n$ 3) and stakeholders ( $n$ 13) at a discussion session to verify their credibility. This helped to fine-tune the interpretation, and confirmed the main results.

\section{Results}

Among the households, thirty-one participated regularly in CPFS and twenty-four were not participating. Respondents were mainly female, aged 40 years and older, and their education level was less than a bachelor's degree. The great majority (80\%) had an annual family income of less than $\$ 15000$ CAD (about \$11400 USD at the time of the study) (Table 1 ). The majority of stakeholders were at least 40 years old, and almost two-thirds 
Table 1 Profile of households participating in the study ( $n$ 55)

\begin{tabular}{|c|c|c|}
\hline Characteristics & $n$ & $\%$ \\
\hline \multicolumn{3}{|l|}{ Age (years) } \\
\hline $20-29$ & 12 & 22 \\
\hline 30-39 & 10 & 18 \\
\hline $40-49$ & 18 & 33 \\
\hline $50+$ & 15 & 27 \\
\hline \multicolumn{3}{|l|}{ Sex } \\
\hline Female & 44 & 80 \\
\hline \multicolumn{3}{|l|}{ Type of household } \\
\hline No children & 26 & 47 \\
\hline Single-parent & 16 & 29 \\
\hline Two-parent & 13 & 24 \\
\hline \multicolumn{3}{|l|}{ Education } \\
\hline$<$ Bachelor's degree & 46 & 84 \\
\hline Bachelor's degree and + & 9 & 16 \\
\hline \multicolumn{3}{|l|}{ Housing* } \\
\hline House or multi-dwelling unit & 8 & 15 \\
\hline Apartment & 25 & 45 \\
\hline Low-cost housing & 7 & 13 \\
\hline Cooperative & 13 & 24 \\
\hline Other & 2 & \\
\hline \multicolumn{3}{|l|}{ Primary source of income } \\
\hline Social assistance & 20 & 36 \\
\hline Salary & 15 & 27 \\
\hline Employment assistance & 5 & \\
\hline Retirement or old age pension & 3 & \\
\hline Other (e.g. student loan, child tax credit) & 12 & 22 \\
\hline \multicolumn{3}{|l|}{ Total income (12 months) $\dagger$} \\
\hline$<\$ 15000$ & 44 & 80 \\
\hline$\geq \$ 15000$ & 10 & 18 \\
\hline \multicolumn{3}{|l|}{ Food insecurity } \\
\hline Affirmative according to CCHS questions & 55 & 100 \\
\hline
\end{tabular}

*Owner of housing: 5 (9\%).

tOne missing datum.

were female. Over three-quarters had an education level of a bachelor's degree or higher. The majority (78\%) had never had to resort to any form of food security programming in their life (Table 2).

\section{Three categories of needs related to food security}

Three main categories of needs stood out: needs specific to food security, conditions necessary for achieving food security, and related needs that reflected the more general living conditions of the households.

\section{Needs specific to food security}

Almost all the respondents (95\% of households and 93\% of stakeholders) mentioned at least one need specific to food security (Table 3). Adequate food and diet quality was among the needs most often mentioned by households and stakeholders. All respondents expressed this need using similar descriptors, e.g. variety, a balanced diet, better quality food (e.g. more fresh produce, biological food) or food that corresponded more to preferences:

Balanced, there's no other word for it, because... I used to have a balanced diet, and...see, everyone should have the right to that... it's obvious.

(Household)

This need, however, was brought out in a much more striking way by households (84\%) than stakeholders
Table 2 Profile of stakeholders $(n 58)^{\star}$

\begin{tabular}{lrr}
\hline Characteristics & $n$ & $\%$ \\
\hline Age (years) & & \\
$20-29$ & 2 & 3 \\
$30-39$ & 7 & 12 \\
$40-49$ & 18 & 31 \\
$\quad 50+$ & 31 & 53 \\
Sex & 35 & 60 \\
$\quad$ Female & & 22 \\
Education* & 13 & 76 \\
$\quad$ Bachelor's degree & 44 & 22 \\
$\quad$ Bachelor's degree and + & 13 & 78 \\
$\quad$ Already ussistance & 13 & \\
$\quad$ Never used it & 45 & \\
\hline *One missing datum. & &
\end{tabular}

Table 3 Needs of food-insecure households as expressed by households ( $n$ 55) and perceived by stakeholders ( $n$ 59)

\begin{tabular}{|c|c|c|c|c|}
\hline \multirow[b]{2}{*}{ Category of need } & \multicolumn{2}{|c|}{ Households } & \multicolumn{2}{|c|}{ Stakeholders } \\
\hline & $n^{\star}$ & $\%$ & $n$ & $\%$ \\
\hline \multicolumn{5}{|l|}{ Food security needs } \\
\hline Quality of diet & 46 & 84 & 33 & 56 \\
\hline Regular \& sustainable access & 20 & 36 & 22 & 37 \\
\hline Social roles & 15 & 27 & 16 & 27 \\
\hline Sufficient quantity of food & 6 & 11 & 36 & 61 \\
\hline Control over the situation & 2 & 4 & 30 & 51 \\
\hline Dignity & 1 & 2 & 12 & 20 \\
\hline Physical well-being & 0 & 0 & 3 & 5 \\
\hline Total of different respondents & 52 & 95 & 55 & 93 \\
\hline Total mentions & 90 & & 152 & \\
\hline Ratio: mentions/respondent & $1 \cdot 6$ & & $2 \cdot 6$ & \\
\hline \multicolumn{5}{|l|}{ Conditions needs } \\
\hline Income; economic accessibility & 44 & 80 & 48 & 81 \\
\hline Employment & 17 & 31 & 18 & 31 \\
\hline Housing & 12 & 22 & 23 & 39 \\
\hline Geographic accessibility & 6 & 11 & 5 & 8 \\
\hline Total of different respondents & 52 & 95 & 55 & 93 \\
\hline Total mentions & 79 & & 94 & \\
\hline Ratio: mentions/respondent & $1 \cdot 4$ & & $1 \cdot 6$ & \\
\hline \multicolumn{5}{|l|}{ Related needs } \\
\hline Peripheral needs & 17 & 31 & 37 & 63 \\
\hline Services & 13 & 24 & 33 & 56 \\
\hline Health and hygiene & 12 & 22 & 9 & 15 \\
\hline Leisure activities; social contacts & 7 & 13 & 33 & 56 \\
\hline Total of different respondents & 30 & 55 & 53 & 90 \\
\hline Total mentions & 49 & & 112 & \\
\hline Ratio: mentions/respondent & 0.9 & & 1.9 & \\
\hline
\end{tabular}

${ }^{*} n$, number of different respondents who made at least one mention related to a sub-category of need (e.g. quality of diet). The same respondent may have expressed more than one need related, e.g., to food security needs.

(56\%); $40 \%$ of the households even considered it to be the most important need (result not shown). In contrast, many stakeholders thought that the households needed a sufficient quantity of food $(61 \%)$ and that it was their most important need ( $27 \%$ ), e.g. the necessary minimum for survival, enough for the children, enough to satisfy 
them so no one in the household would feel hungry. One stakeholder recapitulated this by saying:

I get the impression that quality ranks last, since really it's eating and getting food that are the primary needs.

(Manager)

Households placed the need for enough food for survival much further behind: $11 \%$ of respondents mentioned it, and only $4 \%$ considered it to be their greatest need. Besides the need for quality, several other needs were mentioned more prominently by households than by stakeholders: a regular and sustainable access to food $(36 \%)$, and a food situation that would permit them to assume their social roles (27\%), such as being able to invite family and friends over for a decent meal.

Certain needs were practically never alluded to by the households, compared to the stakeholders. For example, the need for a feeling of control or independence with respect to one's food situation was clearly expressed more often by the stakeholders $(51 \%, v .4 \%$ households):

(...) being in control of what happens to us. So that applies on the level of... lodging, it applies on the level of food, being able to choose what food you are going to eat.

(Community worker)

\section{Conditions necessary for achieving food security}

Besides the needs specific to food security, a set of conditions perceived to be necessary for achieving it was revealed (Table 3). In both groups, these conditions were mainly financial (80\%), whether it was better financial resources or better economic access to food (e.g, more affordable foods):

(...) to have food security and to be able to feed your children like other people, well, that takes money! (...) So let's give them a decent income, and then these people will be able to sort themselves out.

(Community worker)

However, few stakeholders (12\%) clearly feared that some households, who would attach little importance to food or who lacked skills, would not be able to improve their food situation despite increased income:

(...) I have the impression that some of them...they would get some money (...) then that would be it...they still wouldn't eat properly! And the money would just be spent on other things!

(Community worker)

\section{Related needs}

The stakeholders (90\%) were far more numerous than the households ( $55 \%$ ) in referring to related needs (needs that were peripheral to the very food situation). A need for various kinds of learning (e.g. culinary; budgeting skills) was identified by over half the stakeholders ( $51 \%$ ), $v$. only $5 \%$ of the households. The stakeholders stood out not only because of the number of mentions but also by the very way they spoke about the need for learning: instead of translating a household's conscious expression of this need, there was a perception that households 'should' learn more about nutrition and household management in order to solve their problems:

(...) it's a need for better management, you can't work miracles with it, but it's incredible how they just don't manage things. It has an effect on how you eat; if you spend all your money on everything else, on paying bills and all that, well, for sure you're not going to have enough money for...food, are you? (...) I think that they need it, yes they need it. They don't perhaps always see it that way, but you have to make them aware of it.

(Donor agency)

Stakeholders also perceived much more frequently than households that the latter needed services such as food donations or collective kitchens to improve their food situation ( $56 \%$ v. $24 \%$ households). This was particularly the case with persons who worked in CPFS: $63 \%$ of them thought that households needed them, $v$. $47 \%$ of managers and $50 \%$ of donor agencies (results not shown).

\section{Perception of activities from the standpoint of food security}

The households who regularly participated in CPFS ( $n$ 31) openly expressed the degree of fulfilment of their needs through their participation in these programmes (Table 4), as the stakeholders gave their perception of the general appreciation of households regarding CPFS (Table 5).

\section{Quality and access: major needs neglected}

For the households (Table 4), the total of mentions indicate that, despite much positive perceptions ( $n$ 308), the sum of mentions alluding to partial fulfilment or no fulfilment followed close behind ( $n$ 284). All respondents

Table 4 Assessment of food security activities by participating households ( $n$ 31)

\begin{tabular}{lrrr}
\hline & \multicolumn{3}{c}{ Total mentions $(n)^{*}$} \\
\cline { 2 - 4 } Aspects & + & $+/-$ & - \\
\hline Sufficient quantity of food & 15 & 30 & 6 \\
Acceptable quality of food & 44 & 49 & 29 \\
Regular and sustainable access & 33 & 23 & 18 \\
Better control over one's food situation & 66 & 12 & 7 \\
Contribution to social life (during the activity) & 42 & 7 & 7 \\
Contribution to social life (outside the activity) & 14 & 1 & 17 \\
Feeling of physical well-being & 21 & 6 & 22 \\
Feeling of dignity & 32 & 8 & 8 \\
Other & 31 & 17 & 17 \\
Total mentions & 308 & 153 & 131 \\
\hline${ }^{*}+$, fulfilled; $+/-$, some reservations, partially fulfilled;,- unfulfilled.
\end{tabular}


Table 5 Stakeholder perception of household assessment of food security activities ( $n$ 59)

\begin{tabular}{lrr}
\hline Perceived satisfaction & $n$ & $\%$ \\
\hline Satisfied & 32 & 54 \\
Some reservations & 19 & 32 \\
Dissatisfied & 0 & 0 \\
Does not know & 7 & 12 \\
No response & 1 & 2 \\
\hline
\end{tabular}

expressed some reservations or outright unfulfilment with at least one aspect of the activities:

A participant summed up this way:

(...) personally, I didn't really find that they met my needs. (...) it was equivalent to about three or four days of food. So, three to four days out of the month, sure it would perhaps save me about $\$ 20$, but it wasn't enough to say that it met my needs.

I participate in these kitchens because I have to, because if there were a way to get out of them....

Unfulfilment mainly had to do with the most spontaneously expressed needs in the preceding section of the interview, which were the quality of food and the regularity/ sustainability of access to food (Tables 3 and 4):

(...) too often it's the same old stuff; it's important for that to change, and that the food be different, that there be more variety, much more variety.

(...) it's regular - yes and no - because it's once a month. So that if you don't go or if you forget, or if you can't go because no one can go [in your place], well then, you don't get anything, not a single thing. That's what's too bad, that the purchasing group is just once a month.

\section{Combination of several interventions: beneficial, but} still insufficient

Some households specified that various aspects of their needs were only met if they participated in more than one activity, which provided a certain complementarity. In fact, $71 \%$ of the households were participating in more than one activity, whether it was CPFS or a combination of these with a food donations intervention. Despite widespread participation in various programmes, the overall accounts (Table 4) still suggest that even a combination of several activities was insufficient to meet adequately their food security needs.

\section{Short-term effects}

Households often expressed a positive assessment ( $n 42$ mentions) of the social interaction in CPFS. However, it is necessary to distinguish between social life during the activity and outside the activity (Table 4). Although the households appreciated these opportunities for lessening their feelings of loneliness, there were few positive mentions ( $n$ 14) of a contribution to their outside social life (e.g. food obtained made it possible to invite people over for meals).
Also, despite that numerous positive mentions had to do with an improvement in the feeling of control over the food situation, it was mostly described as being ad boc, such as providing access to food and thus freeing up a few dollars in the weekly or monthly budget. A participant remarked that this temporary control in no way solved the deeper cause of her food insecurity, and even created an underlying feeling of dependence:

Going to the kitchens reduces pressure on the budget, but it creates dependence because the problem that forces me to go there hasn't been resolved. (...) until we're able to get out of the hole we're in, until my husband is able to get... a half-decent allowance, and I'm able to find a half-decent job, only then perhaps we'll be able to stop being dependent.

\section{Idealised stakeholder views}

None of the stakeholders perceived that the households could be downright dissatisfied with the CPFS (Table 5). Ten stakeholders even mentioned that the fact that people returned regularly to the activities was a sign of appreciation:

I think that they're very satisfied. The proof is that there are people who've been coming for a long time. I've been told it's the abundance. So... it depends on what they've experienced. No, they're very satisfied.

(Donor agency)

However, other stakeholders (32\%) were aware of the limited contribution of the activities:

(...) the collective kitchen was not invented to make you richer. It was invented to help feed you better with what you have. If you want to get richer, well you have to think about increasing your income and managing your expenses better (...) But... this cannot make a huge difference. It can't be, if your income is below the low-income threshold, it's going to remain below the low-income threshold even if you manage your money better.

(Manager)

Nevertheless, there is still an overall divergence: the households express an inadequate fit between their needs and the CPFS, but if certain stakeholders seem to be aware of this, the majority of them could not detect all the signs of discontentment.

\section{Discussion}

\section{A different view of food security needs and community programmes}

The higher ratio of needs mentioned per respondent among the stakeholders may be influenced by the fact that households were interviewed about their own needs, though 
stakeholders could talk about a range of households, then enunciating more different needs. However, this factor alone cannot explain the main divergences between the perceptions of both groups.

Regarding the needs specific to food security, the quality of food came out very strongly among the households. As a matter of fact, food insecurity is seen as a significant barrier to a healthy diet in various studies ${ }^{(28-31)}$. However, although stakeholders spoke significantly about the need for quality, their vision of households' primary need was a basic amount of food. This apparent overestimation by stakeholders of the importance of a minimum amount of food $v$. other needs could explain partly why they were often under the impression that households were positive about CPFS, as though people would tell themselves that they were already getting more to eat than they would have without them. This point of view is similar to that observed among other stakeholders at food counters ${ }^{(17,32)}$ : by putting forward the idea that, without food donations, households would suffer hunger, these workers may be led to dissociate themselves from the needs of their clients and even consider junk food as adequate donations. Compared to what was expressed by the households in our sample, the perception of stakeholders seems incorrect: the households require more than simple food intake to be satisfied with an activity. However, many of these participatory activities still depend on food donations ${ }^{(20)}$. This limits the ability of participants to choose foods that would suit their needs and preferences; moreover, they are constrained to accept food that is increasingly defined solely by store surpluses $^{(33)}$. Overall, these activities would, therefore, not be able to adequately meet the need for quality that was so clearly expressed by households, but underestimated by stakeholders. These results are similar to the views expressed by other authors ${ }^{(17,32)}$ who emphasised that, in the midst of programmes, needs could remain invisible and unmet, particularly the need for an adequate nutrition on a day-to-day basis.

More than half of the stakeholders thought that the households needed to feel a better control over their food situation, whereas only two households spontaneously expressed such a need. In fact, the households only talked about control when they were questioned about it in the section of the interview about assessment of activities. Several community workers and managers referred to their organisations as adopting an approach based on empowerment, and several donor agencies indicated that, among their criteria for funding interventions, an empowerment approach was generally looked upon favourably. According to the Quebec Collective Kitchens Association ${ }^{(34)}$, collective kitchens make it possible to 'value self-sufficiency and empowerment'. It is possible that the omnipresence of this concept in the stakeholders' ideology could have led them to more easily believe that the households would consciously feel a need to take control of their food situation. They are not necessarily wrong, but the households seem to have expressed things differently, declaring strongly that they needed better financial conditions to support their own food needs, which is related to the notion of control. A few stakeholders believed that the concept of empowerment was a bit overused and that it was possible that CPFS pretended that they practised empowerment without actually applying this philosophy in day-to-day operations. One community worker was of the opinion that, because certain programmes relied mainly on food donations, they could not provide an environment that fostered a transfer of power to participants. Another community worker thought that the benefits of participating in activities did not carry over in the long term once participation ended, as numerous households mentioned. Even if CPFS can provide an increase in food resources, skill development, and mutual support, this cannot replace the achievement of real control that would depend primarily on better financial conditions. This is in line with several authors ${ }^{(20,35,36)}$ showing that CPFS have a limited potential for solving food insecurity related to severe and chronic poverty since they do not significantly change economic conditions. Even while adopting a discourse that promotes social justice, approaches based on empowerment may sometimes involve community participation that cannot mitigate the most severe social and/or environmental problems ${ }^{(37)}$.

Several stakeholders do not, overall, seem aware of the aspects of the CPFS that could be less appreciated by households. Some of them stated themselves that they were poorly informed about the level of household appreciation. They relied, for example, on the perception of those working in the area, whereas this perception can itself be shaded by differences or prejudices about the reality experienced by households ${ }^{(32)}$. Other stakeholders (12\%) confessed that they were totally ignorant of the households' point of view. The dissemination of information among the various types of stakeholders did not always seem to reach the grassroots level. Thus, some had to rely on indirect (e.g. documents), and sometimes incomplete sources of information; this was observed elsewhere in a study on local programme providers' perspectives on nutrition needs among the elderly ${ }^{(38)}$. Since numerous stakeholders do not have the same perception of household needs as do the households themselves, this can fuel a divergence in their perception of the contribution of so-called food security activities in meeting these needs. For certain stakeholders, the fact that households frequent these services regularly is in itself sufficient to affirm that they are satisfied. However, most of the time their participation was motivated by a feeling of obligation, which does not necessarily mean appreciation. Rather than being a sign of appreciation, their recurrent participation could give rise to the reflection that the households remain in a position of food insecurity despite these programmes. 


\section{Financial resources: necessary, but uncertain impact according to stakebolders}

As emphasised by both households and stakeholders, financial resources are a necessary condition for achieving a satisfactory and stable food situation. This is in agreement with the observations of Glanville and McIntyre ${ }^{(28)}$ who showed that a lack of resources for buying food constitute a major obstacle to a healthy diet, even for reaching the minimum portions recommended by the Canada's Food Guide. Food security depends on income security ${ }^{(17)}$. Others have observed that it becomes practically impossible, despite numerous individual strategies, to eat adequately through conventional means (food stores) when government allowances are basically insufficient ${ }^{(39,40)}$. Within our sample, these economic needs were primarily expressed in terms of an increase in general financial resources, employment or a decrease in the cost of basic food products.

Several stakeholders, particularly some managers and donor agencies, are aware of the importance of having access to sufficient financial resources. Nevertheless, other stakeholders remained uncertain about the ability of the households to improve their own situation, even with increased income. In fact, more than a half mentioned that the households would require various kinds of learning to improve their food situation, whereas this was hardly alluded to by households. Some stakeholders stated categorically that even with an increased income, households would not necessarily have a better food situation, since some of them would still not consider food to be important or would not be in any better position to manage their diet properly. It seemed, therefore, that there was a tendency on the part of some stakeholders to believe that some of the households lacked various abilities and that this hampered their chances of improving their situation. As other stakeholders in the sample stated, certain prejudices about lowincome and food-insecure households persist, even among field workers. Similarly, it was noted elsewhere ${ }^{(39,41)}$ that the intervention milieu dealing with low-income households was not always impervious to society's ideology of individualism. As a result, some professionals intervene in order to change the 'disabilities' of individuals while ignoring the impact of their social environment on these apparent disabilities. In contrast, authors have observed from time spent with low-income households that these persons generally develop ingenious ways of making ends meet with their paltry financial resources ${ }^{(39,42)}$. In a study of fruit and vegetable consumption in a low-income population, an intervention that simply consisted in an offer of coupons to improve economic access to fruits and vegetables had a greater impact on consumption than did an education-based intervention ${ }^{(43)}$. The uncertainty about the impact of a better income could also help explain why these stakeholders, and in particular the community workers, more often believed that households needed community services to assist them in achieving food security, in contrast to what households themselves stated. On the other hand, the fact that many of these stakeholders worked in these very activities could explain the importance they attached to them.

Globally, the existence of various differences between the perceptions of households and stakeholders, in terms of both household needs and the assessment of CPFS, makes one wonder up to what point the stakeholders have had the opportunity or the resources to properly assess the reality of food-insecure households. A study such as this one, which questions households directly, can help to provide an authentic basis for stakeholders who wish to develop efficacious interventions. The results also highlight the need to evaluate the overall effect of these interventions on the various aspects of household food security. The action of most of the CPFS remains more on an individual scale, and for the moment they do not appear to correspond completely to household needs. The results emphasise that CPFS cannot replace deeper measures that would act proactively on the environment of households, as would do more global approaches that take social structures into account and seek to change public policies in order to provide conditions whereby households can support their feeding without assistance ${ }^{(44)}$. The results thus accentuate the fact that there is a need to reinforce action for social change and prevention of food insecurity. We are of the opinion of Health Canada ${ }^{(2)}$ that establishing sustainable food security for households requires acting on income-related factors. On the local level, following the Montreal Round Table on Hunger ${ }^{(17)}$, workers in the area of food security could refuse to assume the role of simply being 'poverty managers' and seek to adopt a common outlook in which food security would be an objective to achieve within a global vision of social justice.

\section{Acknowledgements}

Conflict of interest: There are no conflicts of interest in this study.

Authorship responsibilities: A.-M.H. and C.M. designed the study and planned the article. A.-M.H. also supervised all the research steps and writing. A.B. participated in the data collection and analysis and drafted the article. All authors read, commented successive drafts and approved the final manuscript.

Acknowledgements: We are grateful for the financial support provided by the Fonds québécois de la recherche sur la société et la culture.

\section{References}

1. Raphael D (2000) Health inequalities in Canada: current discourses and implications for public health action. Crit Public Health 10, 193-216.

2. Health Canada (2007) Canadian Community Health Survey - Cycle 2.2, Nutrition (2004). Income-Related 
Household Food Security in Canada, p. 118. Ottawa: Office of Nutrition Policy and Food Promotion.

3. Tarasuk VS (2001) Household food insecurity with hunger is associated with women's food intakes, health and household circumstances. J Nutr 131, 2670-2676.

4. Tarasuk V (2005) Household food insecurity in Canada. Top Clin Nutr 20, 299-312.

5. Rose D (1999) Economic determinants and dietary consequences of food insecurity in the United States. $J$ Nutr 129, 517S-520S.

6. Power E (2005) Individual and household food insecurity in Canada: position of dietitians of Canada. Can J Diet Pract Res 66, 43-46.

7. Bartfeld J \& Dunifon R (2005) State-Level Predictors of Food Insecurity and Hunger Among Households With Children. Washington, DC: US Department of Agriculture, Economic Research Service.

8. Lee JS \& Frongillo EA Jr (2001) Nutritional and health consequences are associated with food insecurity among US elderly persons. J Nutr 131, 1503-1509.

9. Olson CM (1999) Nutrition and health outcomes associated with food insecurity and hunger. $J$ Nutr 129, 521S-524S.

10. Tarasuk V (2004) Health implications of food insecurity. In Social Determinants of Health - Canadian Perspectives, pp. 187-200 [D Raphael, editor]. Toronto: Canadian Scholars' Press Inc.

11. Tarasuk VS \& Beaton GH (1999) Women's dietary intakes in the context of household food insecurity. J Nutr 129, 672-679.

12. Che J \& Chen J (2001) Food insecurity in Canadian households. Health Rep 12, 11-22.

13. Cook JT (2002) Clinical implications of household food security: definitions, monitoring, and policy. Nutr Clin Care 5, 152-167.

14. Cook JT, Frank DA, Berkowitz C et al. (2004) Food insecurity is associated with adverse health outcomes among human infants and toddlers. J Nutr 134, 1432-1438.

15. Hamelin AM, Habicht JP \& Beaudry M (1999) Food insecurity: consequences for the household and broader social implications. J Nutr 129, 525S-528S.

16. Lemieux V (1997) Conditions à l'adoption de politiques de sécurité alimentaire au Québec. In L'action Communautaire et les Politiques pour la sécurité Alimentaire: une Question Sociale et de Santé, pp. 75-81 [H Delisle and AM Hamelin, editors]. Montréal: Association canadiennefrançaise pour l'avancement des sciences.

17. Rock M (2006) 'We don't want to manage poverty': community groups politicise food insecurity and charitable food donations. Promot Educ 13, 36-41.

18. Canadian Association of Food Banks (2002) HungerCount 2002 - Eating their words: government failure on food security. In Canada's Annual Survey of Emergency Food Programs, pp. 1-21. Toronto: CAFB (prepared by Beth Wilson with Emily Tsoa).

19. Fano TJ, Tyminski SM \& Flynn MA (2004) Evaluation of a collective kitchens program: using the Population Health Promotion Model. Can J Diet Pract Res 65, 72-80.

20. Tarasuk V \& Reynolds R (1999) A qualitative study of community kitchens as a response to income-related food insecurity. Can J Diet Pract Res 60, 11-16.

21. Canadian Association of Food Banks (2006) HungerCount 2006. http://www.cafb-acba.ca (accessed December 2006).

22. Bilodeau A (2006) Évaluation de la planification du Programme de subventions en sécurité alimentaire, p. 68. Montréal: Direction de santé publique, Agence de la santé et des services sociaux de Montréal.

23. Kendall A, Olson CM \& Frongillo Jr EA (1995) Validation of the Radimer/Cornell measures of hunger and food insecurity. J Nutr 125, 2793-2801.
24. Statistics Canada (2000) Canadian Community Health Survey - Questionnaire for Cycle 1.1, p. 121. Ottawa: Statistics Canada.

25. Hamelin AM, Beaudry M \& Habicht JP (2002) Characterization of household food insecurity in Quebec: food and feelings. Soc Sci Med 54, 119-132.

26. Krippendorff KH (1980) Content Analysis: An Introduction to its Methodology. Newbury Park, CA: Sage Publications.

27. Miles MB \& Huberman AM (2003) Analyse des données qualitatives, 2nd ed. Paris: De Boeck.

28. Glanville NT \& McIntyre L (2006) Diet quality of Atlantic families headed by single mothers. Can J Diet Pract Res 67, $28-35$.

29. Kirkpatrick S \& Tarasuk V (2003) The relationship between low income and household food expenditure patterns in Canada. Public Health Nutr 6, 589-597.

30. McIntyre L, Glanville NT, Raine KD, Dayle JB, Anderson B \& Battaglia N (2003) Do low-income lone mothers compromise their nutrition to feed their children? Can Med Assoc J 168, 686-691.

31. Cristofar SP \& Basiotis PP (1992) Dietary intakes and selected characteristics of women ages $19-50$ years and their children ages $1-5$ years by reported perception of food sufficiency. J Nutr Educ 24, 53-58.

32. Tarasuk V \& Eakin JM (2003) Charitable food assistance as symbolic gesture: an ethnographic study of food banks in Ontario. Soc Sci Med 56, 1505-1515.

33. Tarasuk V \& Eakin JM (2005) Food assistance through 'surplus' food: Insights from an ethnographic study of food bank work. Agric Hum Values 22, 177-186.

34. Quebec Collective Kitchens Association (2005) More than just cooking... . http://www.rccq.org/english/more.html (accessed December 2006).

35. Raine K, McIntyre L \& Dayle JB (2003) The failure of charitable school- and community-based nutrition programmes to feed hungry children. Crit Public Health 13, 155-169.

36. Tarasuk V (2001) A critical examination of communitybased responses to household food insecurity in Canada. Health Educ Behav 28, 487-499.

37. Fraser H (2005) Four different approaches to community participation. Commun Dev J 40, 286-300.

38. Lee JS, Frongillo EA \& Olson CM (2005) Conceptualizing and assessing nutrition needs: perspectives of local program providers. J Nutr Elderly 25, 61-74.

39. Travers KD (1996) The social organization of nutritional inequities. Soc Sci Med 43, 543-553.

40. Williams PL, Johnson CP, Kratzmann MLV, Johnson CSJ, Anderson BJ \& Chenhall C (2006) Can households earning minimum wage in Nova Scotia afford a nutritious diet? Can J Public Health 97, 430-434.

41. McCullum C, Pelletier D, Barr D, Wilkins J \& Habicht JP (2004) Mechanisms of power within a community-based food security planning process. Health Educ Behav 31, 206-222.

42. Hargrove D, Dewolfe JA \& Thompson L (1994) Food security: what the community wants. Learning through focus groups. J Can Diet Assoc 55, 188-191.

43. Anderson JV, Bybee DI, Brown RM, McLean DF, Garcia EM, Breer ML \& Schillo BA (2001) 5 a day fruit and vegetable intervention improves consumption in a low income population. J Am Diet Assoc 101, 195-202.

44. Frohlich KL \& Poland B (2006) Les points d'intervention dans la pratique de la promotion de la santé: l'intérêt d'une approche du contexte social en terme de "modes de vie collectifs". In Promotion de la santé au Canada et au Québec, perspectives critiques, pp. 62-80 [M O'Neill, S Dupéré, A Pederson and I Rootman, editors]. Lévis: Les Presses de l'Université Laval. 